OPEN ACCESS

Edited by:

James T. Murray,

Swansea University Medical School,

United Kingdom

Reviewed by:

Mohammad A. Alfhili,

King Saud University, Saudi Arabia

Shi-Qing Cai,

Institute of Neuroscience, Shanghai

Institute for Biological Sciences (CAS),

China

*Correspondence:

Ingrid Herr

i.herr@uni-heidelberg.de

tORCID:

Ingrid Herr,

orcid.org/0000-0002-2389-6300

Specialty section:

This article was submitted to

Signaling,

a section of the journal

Frontiers in Cell and Developmental

Biology

Received: 28 September 2021

Accepted: 10 November 2021

Published: 03 December 2021

Citation:

Ji H, Qi Z, Schrapel D, Le M, Luo Y, Yan B, Gladkich J, Schaefer M, Liu L and Herr I (2021) Sulforaphane Targets

TRA-1/GLI Upstream of DAF-16/

FOXO to Promote C. elegans

Longevity and Healthspan.

Front. Cell Dev. Biol. 9:784999.

doi: 10.3389/fcell.2021.784999

\section{Sulforaphane Targets TRA-1/GLI Upstream of DAF-16/FOXO to Promote C. elegans Longevity and Healthspan}

\author{
Huihui Ji, Zhimin Qi, Daniel Schrapel, Monika Le, Yiqiao Luo, Bin Yan, Jury Gladkich, \\ Michael Schaefer, Li Liu and Ingrid Herr ${ }^{\star}+$
}

Molecular OncoSurgery, Section Surgical Research, Department of General, Visceral and Transplant Surgery, University of Heidelberg, Heidelberg, Germany

Broccoli-derived isothiocyanate sulforaphane inhibits inflammation and cancer. Sulforaphane may support healthy aging, but the underlying detailed mechanisms are unclear. We used the $C$. elegans nematode model to address this question. Wild-type and 4 mutant $C$. elegans worm strains were fed in the presence or absence of sulforaphane and E. coli food bacteria transfected with RNA interference gene constructs. Kaplan-Meier survival analysis, live imaging of mobility and pharyngeal pumping, fluorescence microscopy, RT-qPCR, and Western blotting were performed. In the wild type, sulforaphane prolonged lifespan and increased mobility and food intake because of sulforaphane-induced upregulation of the sex-determination transcription factor TRA-1, which is the ortholog of the human GLI mediator of sonic hedgehog signaling. In turn, the tra-1 target gene daf-16, which is the ortholog of human FOXO and the major mediator of insulin/IGF-1 and aging signaling, was induced. By contrast, sulforaphane did not prolong lifespan and healthspan when tra-1 or daf-16 was inhibited by RNA interference or when worms with a loss-of-function mutation of the tra-1 or daf-16 genes were used. Conversely, the average lifespan of $C$. elegans with hyperactive TRA-1 increased by $8.9 \%$, but this longer survival was abolished by RNAi-mediated inhibition of daf-16. Our data suggest the involvement of sulforaphane in regulating healthy aging and prolonging lifespan by inducing the expression and nuclear translocation of TRA-1/GLI and its downstream target DAF-16/FOXO.

Keywords: sulforaphane, aging, C. elegans, TRA-1/GLI, DAF-16/FOXO

\section{INTRODUCTION}

Global population aging is a challenge for worldwide health systems. By 2050, the world's population aged 60 years and older is expected to reach two billion (World Health Organization and Ageing and health, 2018). Life expectancy is increasing because of improved medical care and hygienic standards, infection control interventions, antibiotics, vaccinations, and others. However, the elderly are not necessarily healthier, and many do not match the WHO aims to maintain functional ability that enables wellbeing in older age (Crimmins, 2015; Olshansky, 2018; World Health Organization and Ageing and health, 2018). Aging today is reflected by lifestyle diseases such as heart diseases, diabetes, and 
cancer (Niccoli and Partridge, 2012). A high correlation between cancer and aging occurs because the incidence of cancer increases sharply with age (Sedrak et al., 2021), such as pancreatic ductal adenocarcinoma, one of the deadliest malignant tumors (Sohal et al., 2016; Neoptolemos et al., 2018; Siegel et al., 2021). Therefore, several lifestyle and nutritional strategies aim to promote healthy aging to lower biological age and thereby cancer risk.

Epidemiological studies have indicated that the regular consumption of broccoli and other Brassicaceae family vegetables, such as Brussel sprouts, cabbage, cauliflower, kale, swede, and turnip, can reduce the incidence of many cancer types, including pancreatic cancer (Chan et al., 2005; Heinen et al., 2012). In particular, the bioactive, anti-inflammatory isothiocyanate sulforaphane, which is abundant in broccoli, is particularly well studied (Herr and Büchler, 2010). Sulforaphane acts antioxidative and inhibits insulin/IGF-1 signaling in the nematode Caenorhabditis (C.) elegans (Santín-Márquez et al., 2019; Qi et al., 2021). Additionally, sulforaphane reduces hepatic glucose production, improving glucose control in patients with type 2 diabetes (Axelsson et al., 2017). Recent data even showed that a broccoli diet increased the lifespan of the red flour beetle Tribolium castaneum by 30\% (Grünwald et al., 2013). More specifically, crude extracts of Brassica chinensis, also known as pak choy, enhanced the antioxidant activity in a cell-free system and exerted antiaging effects in C. elegans (Chen et al., 2016). These data suggest a role of sulforaphane in the metabolic regulation of aging, according to the criteria underlying metabolic aging reviewed by Finkel et al., 2015 (Finkel, 2015).

The nonpathogenic nematode C. elegans, originally isolated from garden soil, is a widely used model organism to study aging mechanisms (Shen et al., 2018). The C. elegans genome is completely sequenced (Consortium, 1998), and $60-80 \%$ of human gene homologs in C. elegans have been identified (Kaletta and Hengartner, 2006). Also, maintaining the nematodes in the laboratory is inexpensive and straightforward, no ethical regulations have to be followed, the worm body is transparent, individual cells can be observed well under the microscope, and large population/lifespan studies on aging processes can be completed within approximately 30 days (Zhang et al., 2020). Many C. elegans genes are related to human disorders, and several stable, transgenic altered C. elegans strains with gene mutations are available for a small contribution toward expenses from the Caenorhabditis Genetics Center (CGC) at the University of Minnesota, United States (Ashrafi et al., 2003; Watson et al., 2013). Likewise, C. elegans genes can be inhibited effectively, rapidly, and specifically by RNA interference (RNAi) because this approach only requires feeding RNAi-transfected E. coli food bacteria to the worms.

Most C. elegans worms are self-fertilizing hermaphrodites (XX) that are actually females capable of sperm production (Corsi et al., 2015). Adult male C. elegans worms (XO) are smaller and thinner than hermaphrodites, behave differently, and have a ventral gonad associated with spicules at the tail for mating. Hermaphrodites have a significantly longer lifespan than males that is controlled by the sex-determination pathway and its terminal transcription factor TRA-1 (Hodgkin, 1987;
Pires-daSilva and Sommer, 2004; Grote and Conradt, 2006; Ellis and Schedl, 2007). TRA-1 protein levels are much higher in hermaphrodites than in males, and TRA-1 activity is sufficient to promote the development of hermaphrodites, whereas low TRA-1 activity leads to male development (Schvarzstein and Spence, 2006). Three fem genes directly regulate the expression of tra-1. Loss of function of fem-3 results in the hyperactivity of TRA-1 expression (Szabó et al., 2009; Kutnyánszky et al., 2020) and promotes the development of hermaphrodites (Starostina et al., 2007). TRA-1 is orthologous to the human GLI protein, a mediator of Sonic hedgehog signaling, which is involved in embryonic limb development (Briscoe and Thérond, 2013), but also in tumorigenesis (Coquenlorge et al., 2019), and was most recently identified as a suppressor of endometrial stem cell aging (Cho et al., 2019). Interestingly, recent data have indicated that sulforaphane regulates the self-renewal of pancreatic cancer stem cells by modulating the sonic hedgehog-GLI pathway (Li et al., 2013). Findings from another detailed study suggest that TRA-1 mediates aging in a sex-specific way, partly because of the binding of TRA-1 to the daf-16 locus (Hotzi et al., 2018). DAF-16 is a homolog of the human FOXO transcription factor (Lin et al., 1997) and modulates longevity, stress resistance, development, and resting dauer diapause (Lin et al., 2018; Hou et al., 2019). However, FOXO1 is a tumor suppressor and inhibitor of pancreatic cancer growth (Roy et al., 2010; Pramanik et al., 2014). Thus, the interaction of TRA-1 and DAF-16 in aging and that of their mammalian counterparts in cancer seems likely but requires further clarification.

We investigated whether sulforaphane extends the longevity and healthspan of C. elegans via TRA-1-mediated DAF-16 signaling. We performed lifespan assays using wild-type and mutant nematodes or feeding RNAi oligonucleotides to inhibit TRA-1 or DAF-16 expression. We identified a strong relationship between sulforaphane-induced longevity and enhanced expression of TRA-1 and its downstream target DAF- 16. These data indicate that sulforaphane promotes female/ hermaphrodite development, enhancing the health and longevity of C. elegans.

\section{MATERIALS AND METHODS}

\section{C. elegans Strains}

The C. elegans wild-type reference strains N2/Bristol (Stiernagle, 2006), CB4270 tra-1 (e2200) (Zarkower et al., 1994), CB3844 fem-3 (e2006) IV (Hodgkin, 1986), RA7 (rdEx1) (Mathies et al., 2004), and TJ356 daf-16 (zIs356) IV (Lee et al., 2001; Lin et al., 2001) were obtained from the Caenorhabditis Genetics Center-CGC (University of Minnesota, Minneapolis, MN, United States), and are summarized in Table 1. All worm strains were maintained at $20^{\circ} \mathrm{C}$, except of the CB4270 tra-1 mutant (e2200), which was maintained at $15^{\circ} \mathrm{C}$. According to the instructions of the CGC, this tra-1 mutant needs to be cultured at $15^{\circ} \mathrm{C}$ to obtain hermaphrodites, because this worm strain will become sterile and gonad-defective at $25^{\circ} \mathrm{C}$, due to feminization by smg (NMD) mutations (compare Table 3). 
TABLE 1 | Characterization of $C$. elegans wild-type and mutant strains.

\begin{tabular}{|c|c|c|c|}
\hline $\begin{array}{l}\text { Strain name and } \\
\text { WB ID }\end{array}$ & Genotype & Description & Ref \\
\hline $\begin{array}{l}\text { N2 } \\
00000001\end{array}$ & wildtype & $\begin{array}{l}\text { Isolated } 1951 \text { from mushroom compost in an urban garden by W. L. Nicholas in Bristol. } \\
\text { Development time: } \sim 3 \text { days. Brood size: } ~ 330 \text { eggs. Lifespan: } \sim 3 \text { weeks }\end{array}$ & Stiernagle (2006) \\
\hline $\begin{array}{l}\text { CB4270 } \\
00004546\end{array}$ & tra-1 (e2200) & $\begin{array}{l}\text { Loss-of-function tra- } 1 \text { mutant. Tra- } 1 \text { is the main effector of sex-determination in } \mathrm{C} \text {. elegans; it } \\
\text { inhibits male development and promotes female development. Hermaphrodite at } 15^{\circ} \mathrm{C} \text {, sterile and } \\
\text { gonad-defective at } 25^{\circ} \mathrm{C} \text {, feminized by smg (NMD) mutations. Made by EMS mutagen }\end{array}$ & Zarkower et al. (1994) \\
\hline $\begin{array}{l}\text { CB3844 } \\
00004512\end{array}$ & $\begin{array}{l}\text { fem-3 } \\
\text { (e2006) IV }\end{array}$ & $\begin{array}{l}\text { Fem-3 is required for male development and inhibits TRA-1. The fem-3 (e2006) null-mutation } \\
\text { results in feminization of hermaphrodites at } 15^{\circ} \mathrm{C} \text {, which transform into fertile females at } 25^{\circ} \mathrm{C} \text {, and } \\
\text { maintain at } 15^{\circ} \mathrm{C} \text {. Made by the Jonathan } \mathrm{A} \text {. Hodgkin lab }\end{array}$ & Hodgkin (1986) \\
\hline $\begin{array}{l}\text { RA7 } \\
00031307\end{array}$ & rdEx1 & GFP::tra-1 fusion protein. Maintain by picking gravid rollers. Made by the Laura Mathies lab & Mathies et al. (2004) \\
\hline $\begin{array}{l}\text { TJ356 } \\
00005218\end{array}$ & zls356 IV & $\begin{array}{l}\text { The daf- } 16 \text { gene is fused to a GFP reporter and driven by the daf- } 16 \text { promoter. Made by the A. } \\
\text { Rougvie lab by } \gamma \text {-irradiation. Superficially wild type }\end{array}$ & $\begin{array}{l}\text { Lee et al. (2001); Lin et al. } \\
\text { (2001) }\end{array}$ \\
\hline
\end{tabular}

\section{Culture and Sampling of C. elegans}

C. elegans was cultured on nematode growth medium (NGM: $0.3 \% \mathrm{NaCl}, 1.7 \%$ agar, $0.25 \%$ peptone, $5 \mathrm{mg} / \mathrm{ml}$ cholesterol, $1 \mathrm{mM}$ $\mathrm{KPO}_{4}$, and $1 \mathrm{mM} \mathrm{MgSO}$ ) in plastic dishes (Greiner Bio-One $\mathrm{GmbH}$, Frickenhausen, Germany), which were seeded with a lawn of E. coli OP50 food bacteria (CGC, University of Minnesota, Minneapolis, MN, United States). The E. coli OP50 bacteria were cultured overnight at $37^{\circ} \mathrm{C}$ and diluted to an $\mathrm{OD}_{600}$ concentration of $\sim 1.0$ as described previously (Ke et al., 2020). Afterward, $100 \mu \mathrm{L}$ of the E. coli OP50 suspension was plated on $35 \mathrm{~mm}$ NGM plates for lifespan assays or $300 \mu \mathrm{L}$ on $60 \mathrm{~mm}$ NGM plates to maintain C. elegans. The plates were dried overnight at room temperature. C. elegans was maintained at $20^{\circ} \mathrm{C}$ according to the standard protocol (Brenner, 1974), except for the CB4270 tra-1 (e2200) and CB3844 fem-3 (e2006) strains, which were maintained at $15^{\circ} \mathrm{C}$.

\section{Lifespan Assays}

Lifespan assays were performed as recently described (Qi et al., 2021). For synchronization, 30 gravid C. elegans worms were transferred to new NGM plates supplemented with E. coli OP50 food bacteria to lay eggs for $3 \mathrm{~h}$. Next, the worms were picked and washed. After the hatching of early-stage L1 larvae from the eggs, the larvae developed within approximately $40 \mathrm{~h}$ to late larval stage L4 and were then transferred to new NGM plates containing OP50 food bacteria and $100 \mu \mathrm{M}$ sulforaphane (DL-sulforaphane; $\geq 95 \%$; S4441; Sigma-Aldrich, Manheim, Germany). The control plates contained OP50 bacteria without sulforaphane. Sulforaphane was dissolved in DMSO (AppliChem, Darmstadt, Germany) to a $100 \mathrm{mM}$ stock solution. During the following 9 days, the worms were transferred daily to new NGM plates with OP50 food bacteria \pm sulforaphane to avoid new larvae hatching from laid eggs on the old NGM plates to avoid falsifying the results of the lifespan experiments. From Day 10, the transfer of worms to new plates was performed every second day because older worms lay fewer eggs. The transfer was performed under the microscope: a platinum pick (Neolab, Heidelberg, Germany) was sterilized by passing it through the flame of a Bunsen burner (WLD-TEC, Arenshausen, Germany), and the tip was loaded with a glob of OP50 bacteria by gently scraping through the
TABLE 2 | Primer sequences used to detect $C$. elegans nematode candidate genes.

\begin{tabular}{lcl}
\hline Gene & Type & \multicolumn{1}{c}{ Sequence } \\
tra-1 & F & 5'-ATC ACG CAT GGC GTT GTG AG-3' \\
& R & 5'-CGC CTG TAT GAG TTC TCC GG -3' \\
daf-16 & F & 5'-CCA GAC GGA AGG CTT AAA CT-3' \\
& R & 5'-ATT CGC ATG AAA CGA GAA TG-3' \\
act-1 & F & 5'-CCA GGA AT GCT GAT CGT ATG CAG AA-3' \\
& R & 5'-TGG AGA GGG AAG CGA GGA TAG A-3'
\end{tabular}

F: forward primer; $R$ : reverse primer.

bacterial lawn of the LB agar plate. To select a worm, its body was gently tapped with the pick until the worm adhered to the pick and could be transferred to another plate. Here, the tip of the pick was gently touched to the agar until the worm crawled off the pick. Next, the pick was sterilized for the next round of worm transfer. A worm was considered dead if it stopped moving-even after touching. Worms that exhibited internal hatching or climbed up the wall of the dishes were excluded from the analysis.

\section{RNA Extraction and Real-Time PCR}

Synchronized L4 larvae ( $n=200$ /group) were transferred to fresh NGM plates seeded with a lawn of OP50 food bacteria \pm sulforaphane $(100 \mu \mathrm{M})$, and $24,48,72$, or $120 \mathrm{~h}$ later, the worms were collected, washed $3 \times$ with $\mathrm{M} 9$ buffer $(3 \mathrm{~g}$ of $\mathrm{KH}_{2} \mathrm{PO}_{4}, 6 \mathrm{~g}$ of $\mathrm{Na}_{2} \mathrm{HPO}_{4}, 5 \mathrm{~g}$ of $\mathrm{NaCl}, 1 \mathrm{ml}$ of $1 \mathrm{M} \mathrm{MgSO}_{4}$, in $1 \mathrm{~L}$ of $\mathrm{H}_{2} \mathrm{O}_{\text {bidest }}$ ) (Stiernagle, 2006), and crushed under liquid nitrogen. According to the manufacturer's instructions, total RNA was extracted using the RNeasy Mini Kit (QIAGEN, Hilden, Germany). Next, the high-capacity RNA-to-cDNA ${ }^{\mathrm{TM}}$ Kit (Thermo Fisher Scientific, Hilden, Germany) was applied for reverse transcription. PowerUp ${ }^{\mathrm{TM}}$ SYBR $^{\mathrm{TM}}$ Green Master Mix (Thermo Fisher Scientific, Hilden, Germany) as used to perform RT-qPCR. A $10 \mu \mathrm{L}$ reaction mixture contained $2 \mu \mathrm{L}$ of cDNA, $500 \mathrm{nM}$ of each primer, and $5 \mu \mathrm{L}$ of PowerUp ${ }^{\mathrm{TM}} \mathrm{SYBR}^{\mathrm{TM}}$ Green Master Mix (2x). PCR was performed using the Applied Biosystem $^{\text {TM }}$ 7,500 Real-Time PCR System (Thermo Scientific, Schwerte, Germany) and included denaturation for $2 \mathrm{~min}$ at $95^{\circ} \mathrm{C}$ and 40 cycles of amplification $\left(15 \mathrm{~s}, 95^{\circ} \mathrm{C} ; 15 \mathrm{~s}, 60^{\circ} \mathrm{C} ; 1 \mathrm{~min}, 72^{\circ} \mathrm{C}\right)$. 
C. elegans-specific primers (Table 2) were obtained ready-to-use from Eurofins Genomics (Mannheim, Germany).

\section{Western Blot Analysis}

Synchronized L4 larvae ( $n=200$ /group) of the C. elegans reporter strain RA7 were incubated in NGM agar plates with OP50 food bacteria, $\pm 100 \mu \mathrm{M}$ sulforaphane. After $24,48,72$, or $120 \mathrm{~h}$, the worms were collected and washed $3 \times$ with M9 buffer. The worms were transferred to $\mathrm{H}_{2} \mathrm{O}_{\text {bidest }}$ containing a protease inhibitor mix (Sigma-Aldrich, Manheim, Germany) in Laemmli buffer and boiled at $95^{\circ} \mathrm{C}$ for $5 \mathrm{~min}$, followed by centrifugation for $1 \mathrm{~min}$ at $13,000 \mathrm{~g}$. According to the standard protocol (Wueseke et al., 2014), the protein content was not measured, but the proteins were extracted from the same number of live worms per group ( $\mathrm{n}$ $=200$ ). Next, $50 \mu \mathrm{L}$ of supernatant with protein was loaded per slot of a $10 \%$ SDS polyacrylamide gel, and electrophoresis was performed at $120 \mathrm{~V}$ for $2 \mathrm{~h}$. The gels were blotted to Immobilon ${ }^{\circledR}$ $\mathrm{P}$ transfer membranes (Millipore, Billerica, United States) using a wet transfer system (Bio-Rad, Hercules, United States), followed by incubation with rabbit polyclonal anti-GFP antibody (ab290; Abcam, Cambridge, United States), diluted 1:1,000, or mouse monoclonal anti- $\alpha$ Tubulin antibody (T5168; Sigma-Aldrich, MO, United States), diluted 1:5,000. Anti-mouse IgG and antirabbit IgG secondary antibodies (IRDye ${ }^{\circledR}$ 800CW; LI-COR Biosciences, Lincoln, United States) were diluted at 1:5,000 before use. After washing, the membranes were imaged using an Odyssey ${ }^{\circledR}$ CLx Infrared Imaging System (Li-cor ${ }^{\circledR}$, Lincoln, United States).

\section{Fluorescence Microscopy}

The C. elegans RA7 and TJ356 strains were placed on 2\% agarose pads $(n=5 /$ pad $)$ and paralyzed by adding $50 \mu \mathrm{L}$ of a $10 \mu \mathrm{M}$ levamisole solution (Sigma-Aldrich, MO, United States). Images of the live worms (20/group) were taken using a Leica DMRB fluorescence microscope (Leica, Wetzlar, Germany) equipped with a Thorlabs CS895CU Compact Scientific 8.9 MP color camera (Thorlabs GmbH, Bergkirchen, Germany). The expression levels were quantified by measuring the GFP fluorescence intensity using ImageJ.

\section{RNAi Application}

RNAi-mediated inhibition of C. elegans genes was performed as previously described (Kamath et al., 2001). The tra-1 RNAi and daf-16 RNAi clones were obtained from the C. elegans RNAi feeding library, distributed by Source BioScience (Nottingham, United Kingdom). An RNAi-transfected E. coli HT115 (DE3) clone or a nontransfected E. coli HT115 (DE3) clone was picked from the delivered agar plates and incubated overnight at $37^{\circ} \mathrm{C}$ in $5 \mathrm{ml}$ of LB medium containing $50 \mu \mathrm{g} / \mathrm{ml}$ of ampicillin (Sigma-Aldrich, MO, United States). Feeding plates were prepared using standard NGM agar plates supplemented with $1 \mathrm{mM}$ IPTG and $25 \mu \mathrm{g} / \mathrm{ml}$ of carbenicillin (both from Sigma-Aldrich, MO, United States). RNAi-transfected E. coli HT115 or nontransfected E. coli HT115 control bacteria, $100 \mu \mathrm{L}$ each, at an $\mathrm{OD}_{600}$ concentration of $\sim 1.0$, were seeded onto $35 \mathrm{~mm}$ NGM feeding plates and dried overnight at room temperature. Next, synchronized L4 larvae $(n=30)$ were transferred to plates and kept at $20^{\circ} \mathrm{C}$ for $48 \mathrm{~h}$ to allow the intake of RNAi-transfected food bacteria. Afterward, the gravid adult worms were picked and seeded onto new feeding plates with the same bacteria and laid eggs for $3 \mathrm{~h}$. After that, the adult worms were washed. After hatching, C. elegans larvae proceeded through four larval stages (L1-L4) until the late larval stage L4/young adult stage and were then transferred to new feeding NGM plates for new experiments.

\section{Pharyngeal Pumping Assay}

The frequency of pharyngeal pumping as a measure of appetite and food intake was determined as previously described (Raizen et al., 2012). Synchronized L4 C. elegans larvae ( $=20 /$ group) were maintained on NGM plates containing E. coli OP 50 bacteria, RNAi-transfected E. coli HT115 bacteria, or nontransfected E. coli HT115 control bacteria in the presence or absence of $100 \mu \mathrm{M}$ sulforaphane. The pharyngeal pumping frequency of the terminal pharyngeal bulb of individual worms was counted $60 \mathrm{sec}$ and 3, 6, 9, and 12 days later under an inverted microscope (Leica, Wetzlar, Germany). Additionally, a differential interference contrast microscope (Ni-E, Nikon, Germany) was used to photograph the pharyngeal structure of C. elegans.

\section{Mobility/Body Bending Assay}

Worm mobility was used to reflect the functional state of motor neurons and muscle cells (Mergoud Dit Lamarche et al., 2018), as recently described (Qi et al., 2021). Synchronized L4 C. elegans larvae ( $\mathrm{n}=50$ /group) were maintained on NGM plates containing E. coli OP 50 bacteria or nontransfected or RNAitransfected E. coli HT115 bacteria in the presence or absence of $100 \mu \mathrm{M}$ sulforaphane. The body bends of single worms were counted for $60 \mathrm{~s}$ and 3, 6, 9, and 12 days later, and the number of body bends was calculated as body bends/min. A change in the posterior bulb direction or regular swinging of the head was considered a body bend.

\section{Statistical Analysis}

For Kaplan-Meier survival curves, the $p$ values of differences between groups were tested using the log-rank test. Student's t-test was used to assess differences between two groups. IBM SPSS Statistics 25 software was used to perform statistical analysis. $p<0.05$ was considered statistically significant.

\section{RESULTS}

\section{TRA-1 Is Required for Sulforaphane-Induced Longevity}

To investigate the impact of sulforaphane, which is chemically a sulfur-containing isothiocyanate (Figure 1A), we fed synchronized L4 wild-type C. elegans larvae with E. coli OP50 food bacteria in the presence or absence of $100 \mu \mathrm{M}$ sulforaphane. We chose this sulforaphane concentration because it is considered optimum to treat C. elegans (Qi et al., 2021). The number of worms was recorded daily until no more live worms could be found from Day 33 onwards. Afterward, a Kaplan-Meier 


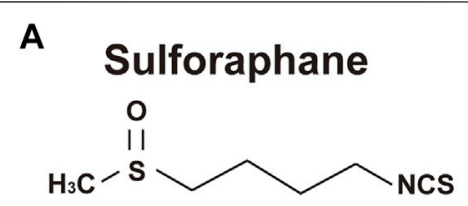

C
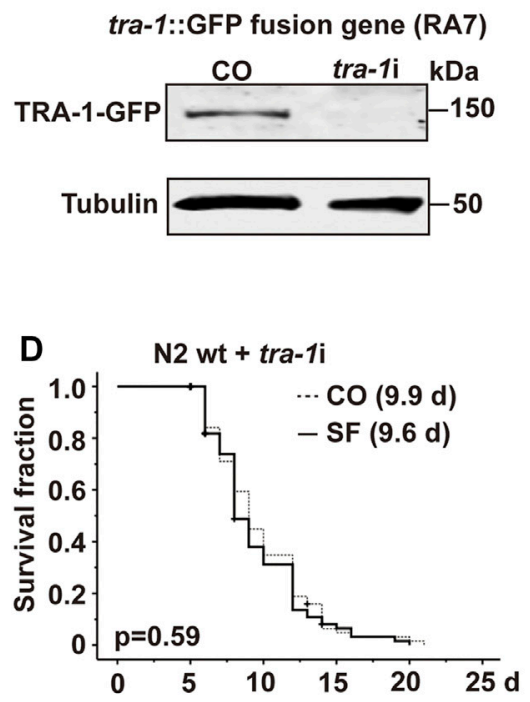
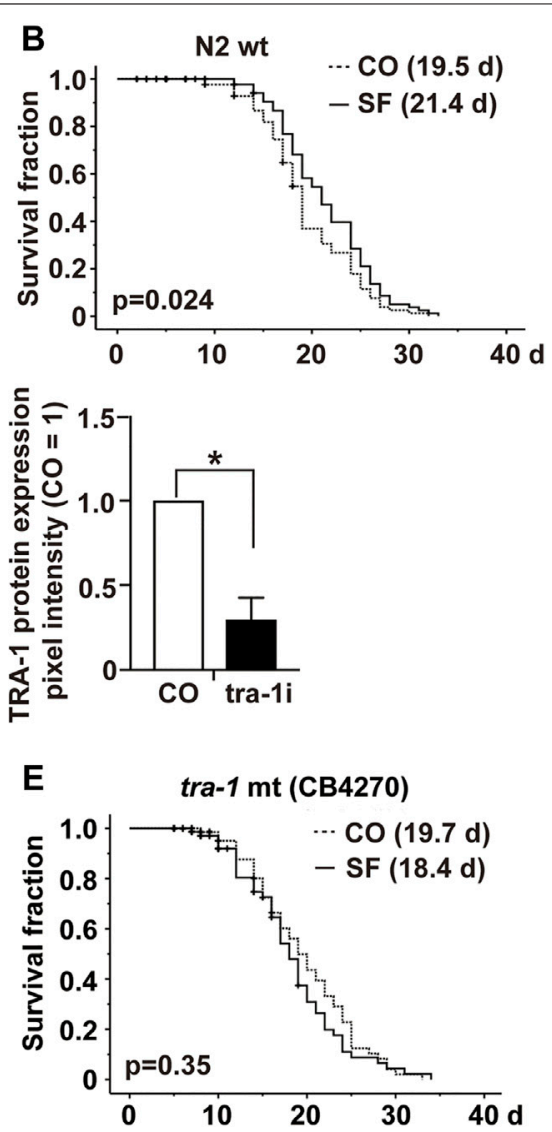

FIGURE 1 | TRA-1 is involved in sulforaphane-induced longevity. (A) Schematic representation of the chemical structure of isothiocyanate sulforaphane. (B) Synchronized N2 wild-type C. elegans L4 larvae ( $n=100 /$ group) were transferred to NGM plates and maintained at $20^{\circ} \mathrm{C}$. In addition to the regular $E$. coli OP50 food bacteria, the culture plates contained $100 \mu \mathrm{M}$ sulforaphane (SF) or not (CO). The lifespan assay started from the late $\mathrm{L} 4$ larval stage, which was considered Day 0 (0 days). From Day 0 to Day 10, the C. elegans worms were transferred to new NGM plates daily. From Day 10, the worms were transferred every second day. The endpoint was defined as the day when all the worms were dead. In the Kaplan-Meier diagram, the numbers of living and censored worms are shown, and the log-rank test was used to evaluate the statistical significance. (C) Synchronized RA7 C. elegans L4 larvae harboring a tra-1-GFP fusion gene ( $n=200 / g r o u p)$ were fed tra-1 RNAitransduced E. coli HT115 bacteria (tra-1i) or nontransduced E. coli HT115 bacteria (CO). After 48 h, proteins were extracted, followed by Western blot analysis. A GFPspecific antibody was used to target the GFP part of the TRA-1 fusion protein. Tubulin served as a control for equal loading conditions. The protein sizes in kilodaltons $(\mathrm{kDa})$ are provided (upper part). The relative pixel intensity was analyzed using ImageJ. The intensity of TRA-1-GFP expression was normalized relative to tubulin, and the amount obtained in control C. elegans worms was set to 1, as shown in the diagram on the right with the means, standard deviations and significance. (D) N2 wild-type C. elegans worms were treated as described above and analyzed by Kaplan-Meier survival analysis. The total number of worms in each experiment was 100. (E) KaplanMeier analysis was performed using the CB4270 C. elegans strain with a loss-of-function tra-1 gene. The worms were treated as described above, but maintained at $15^{\circ} \mathrm{C}$, as recommended by the CGC (compare Table 3). Individual $p$ values are given, and $p \leq 0.05$ was considered statistically significant.

survival analysis was performed. Sulforaphane significantly increased the mean lifespan of wild-type worms to 21.4 days compared with 19.5 days of untreated control worms, indicating a 9.9\% longer survival (Figure 1B; Table 3).

To examine the involvement of tra-1 signaling, we inhibited TRA-1 by feeding E. coli HT115 bacteria transfected with tra-1 RNAi constructs to the C. elegans RA7 strain, which expresses a TRA-1-GFP fusion protein (Mathies et al., 2004). After $48 \mathrm{~h}$, the proteins were extracted (200 worms/group), and Western blot analysis was performed to ensure the effectiveness of RNAimediated inhibition of TRA-1. A representative Western blot image is shown along with a diagram of the pixel intensities of the TRA- 1 band relative to the tubulin pixel intensity, which served as a control for equal conditions. This confirmed a significant inhibition of TRA-1-GFP expression of approximately $70 \%$ (Figure 1C).

Next, we set up a series of lifespan assays to examine the longevity of tra-1(-) mutant worms relative to the presence of sulforaphane. Kaplan-Meier survival analysis revealed that the mean lifespan of tra-1 RNAi-treated nematodes that received sulforaphane was 9.6 days compared with 9.9 days of control worms, with no significant difference (Figure 1D). To further confirm the involvement of tra-1 signaling in lifespan, the tra1(-) mutant CB4270 worm strain was evaluated by Kaplan-Meier survival analysis, resulting in a survival of 18.7 days in the presence of sulforaphane and 19.7 days in untreated control worms, with no significant difference (Figure 1E). These data suggest that sulforaphane-induced 
TABLE $\mathbf{3}$ | Sulforaphane effects on the lifespan of $C$. elegans strains.

\begin{tabular}{|c|c|c|c|c|c|c|c|}
\hline C. elegans strains & Temperature $\left({ }^{\circ} \mathrm{C}\right)$ & Fig. No. & Exp. No. & Sulforaphane $(\mu \mathrm{M})$ & $\begin{array}{c}\text { Mean } \\
\text { lifespan } \pm \text { SEM (days) }\end{array}$ & $\begin{array}{c}\%,{ }^{\mathrm{a}} \text { Mean increase } \\
\text { (SF treatment) }\end{array}$ & $p$ Value \\
\hline \multirow[t]{3}{*}{ N2 } & 20 & $1 \mathrm{~B}$ & 1 & $\begin{array}{c}0 \\
100\end{array}$ & $\begin{array}{l}16.19 \pm 0.52 \\
18.70 \pm 0.53\end{array}$ & 15.5 & 0.001 \\
\hline & & & 2 & $\begin{array}{c}0 \\
100\end{array}$ & $\begin{array}{l}20.99 \pm 0.52 \\
22.85 \pm 0.47\end{array}$ & 8.9 & 0.037 \\
\hline & & & 3 & $\begin{array}{c}0 \\
100\end{array}$ & $\begin{array}{l}19.47 \pm 0.53 \\
21.40 \pm 0.52\end{array}$ & 9.9 & 0.024 \\
\hline \multirow[t]{3}{*}{$\mathrm{N} 2$ (tra-1i) } & 20 & $1 \mathrm{D}$ & 1 & $\begin{array}{c}0 \\
100\end{array}$ & $\begin{array}{l}9.89 \pm 0.41 \\
9.55 \pm 0.37\end{array}$ & - & 0.485 \\
\hline & & & 2 & $\begin{array}{c}0 \\
100\end{array}$ & $\begin{array}{l}9.62 \pm 0.31 \\
9.65 \pm 0.31\end{array}$ & - & 0.839 \\
\hline & & & 3 & $\begin{array}{c}0 \\
100\end{array}$ & $\begin{array}{c}9.09 \pm 0.41 \\
10.24 \pm 0.59\end{array}$ & - & 0.103 \\
\hline \multirow[t]{3}{*}{ CB4270 } & 15 & $1 \mathrm{E}$ & 1 & $\begin{array}{c}0 \\
100\end{array}$ & $\begin{array}{l}19.70 \pm 0.79 \\
18.43 \pm 0.80\end{array}$ & - & 0.352 \\
\hline & & & 2 & $\begin{array}{c}0 \\
100\end{array}$ & $\begin{array}{l}28.45 \pm 0.89 \\
27.22 \pm 0.90\end{array}$ & - & 0.710 \\
\hline & & & 3 & $\begin{array}{c}0 \\
100\end{array}$ & $\begin{array}{l}27.88 \pm 1.08 \\
28.20 \pm 1.04\end{array}$ & - & 0.766 \\
\hline
\end{tabular}

aMean lifespan: Corresponds to the mean lifespan as measured in the present study.

Summary and statistical analysis of sulforaphane effects on lifespan experiments. N2: Wild-type C. elegans strain; N2 (tra-1i): loss-of-function tra-1 C. elegans strain; CB4270: tra-1(-) mutant C. elegans strain. The mean lifespan values were analyzed by log-rank (Kaplan-Meier) statistical tests. $\mathrm{p}$ values $<0.05$ were considered statistically significant. $\mathrm{p}$ values were calculated for individual experiments $(\mathrm{n}=100)$. All statistical evaluations were calculated using SPSS 25.0. $(-)$ not calculated because the standard deviation was >0.05. SEM: standard error of the mean.

prolongation of the lifespan in C. elegans is dependent on intact tra-1 signaling.

\section{TRA-1 Expression is Upregulated by Sulforaphane}

To determine the effect of sulforaphane on tra-1 expression, we fed synchronized wild-type worms in the presence or absence of sulforaphane. After 24, 48, 72, and $120 \mathrm{~h}$, RNA was isolated, and tra-1 expression was examined by RT-qPCR analysis. The level of tra- 1 was significantly upregulated at $48 \mathrm{~h}$ after sulforaphane feeding, whereas no obvious difference was observed at 24,72 , or $120 \mathrm{~h}$ (Figure 2A). Likewise, the C. elegans RA7 strain, which expresses a TRA-1-GFP fusion protein, was used to identify the effect of sulforaphane on TRA-1 protein expression. Synchronized RA7 $C$. elegans worms were fed with or without sulforaphane. Next, 24, 48, 72 , and $120 \mathrm{~h}$ later, the proteins were extracted, and Western blot analysis was performed using a GFP-specific antibody. We observed that sulforaphane significantly induced TRA-1-GFP expression at each time point, as shown by a representative Western blot image and the evaluation of the mean pixel intensities by ImageJ and relation to the pixel intensities of the tubulin control (Figure 2B, Supplementary Figure S1).

Next, we examined native GFP fluorescence in untreated RA7 nematodes by fluorescence microscopy and counterstained the cell nuclei with DAPI. We observed spots with enhanced fluorescence intensity in intestinal nuclei, indicating the expression and nuclear accumulation of the TRA-1 transcription factor (Figure 2C). To further validate the sulforaphane-increased accumulation of the TRA-1-GFP fusion protein, we fed RA7 worms with or without sulforaphane. Thereafter, 24, 48, 72, and $120 \mathrm{~h}$ later, we counted the green fluorescent spots, indicating nuclear localization of the TRA-1-
GFP fusion protein using fluorescence microscopy. The mean fluorescence intensities were assessed using ImageJ and revealed that sulforaphane further increased the nuclear accumulation of the TRA-1-GFP fusion protein at each time point (Figures 2D,E). These findings suggest that sulforaphane enhances TRA-1 expression.

\section{Sulforaphane Increases the Healthspan via TRA-1}

To evaluate whether TRA-1 serves as a mediator of an increased healthspan after sulforaphane treatment, we analyzed the mobility and pharyngeal pumping rate of $C$. elegans because these features display age-related declines (Collins et al., 2008). To assess appetite and food intake, the pumping frequency of the terminal pharyngeal bulb (Figure 3A) of each worm was documented by microscopy and video recordings at Days 3, 6, 9, and 12 after sulforaphane feeding. However, sulforaphane did not significantly alter the pharyngeal pumping frequency in younger worms at Days 3, 6, and 9; it significantly increased the frequency to $52 \mathrm{pumps} / \mathrm{minute}$ in older worms on Day 12 (Figure 3B). By contrast, untreated wild-type C. elegans worms exhibited 19 pumps/minute at Day 12, a time point at which the healthspan of worms was significantly decreased. Using tra-1 RNAi-treated nematodes and examining the pharyngeal pumping rate in the presence or absence of sulforaphane, we observed no significant differences between the groups at any time point examined (Figure 3C). We would like to mention, that we tried to measure the pharyngeal pumping rate also at Day 12, which was, however, not possible, because tra-1 RNAi transfection dramatically shortened the lifespan and at Day 12 almost all worms were dead, in both, the sulforaphane-treated and -untreated groups (compare Figure 1D). Interestingly, the 

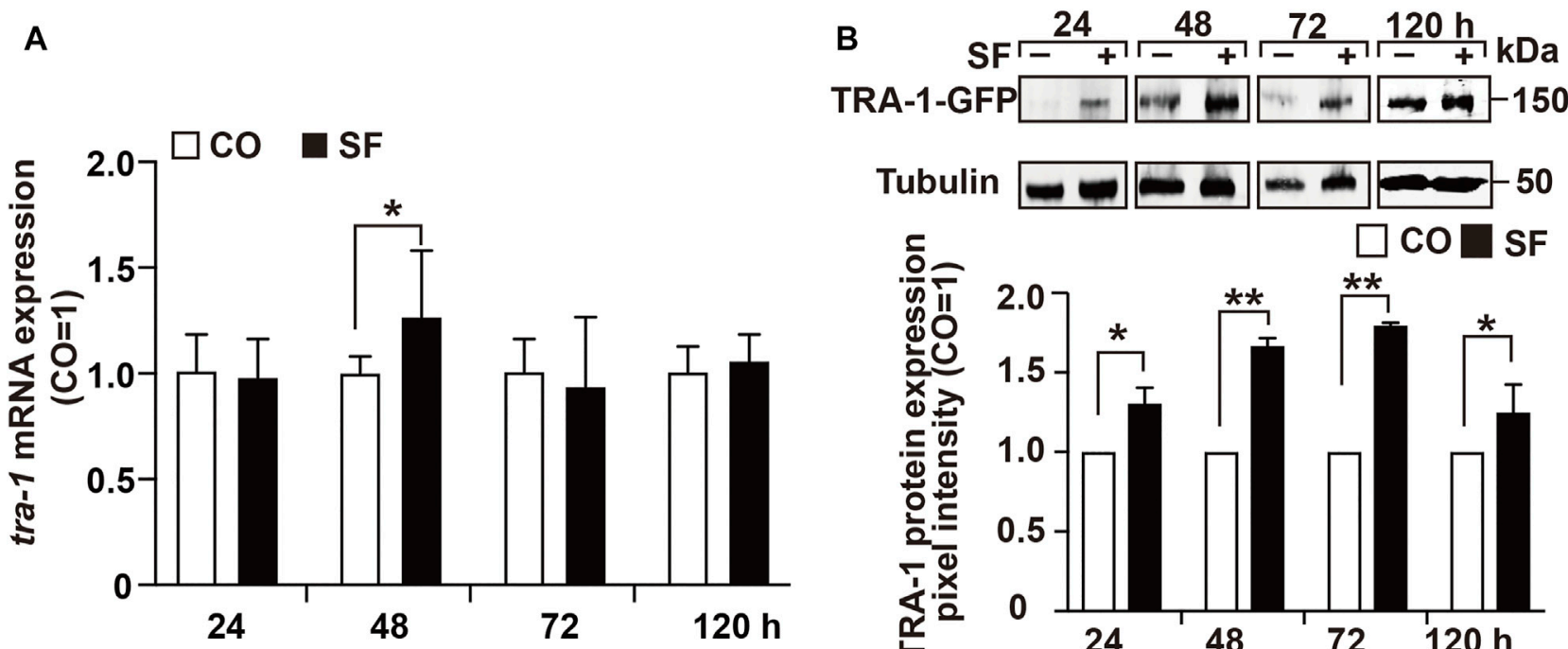

C
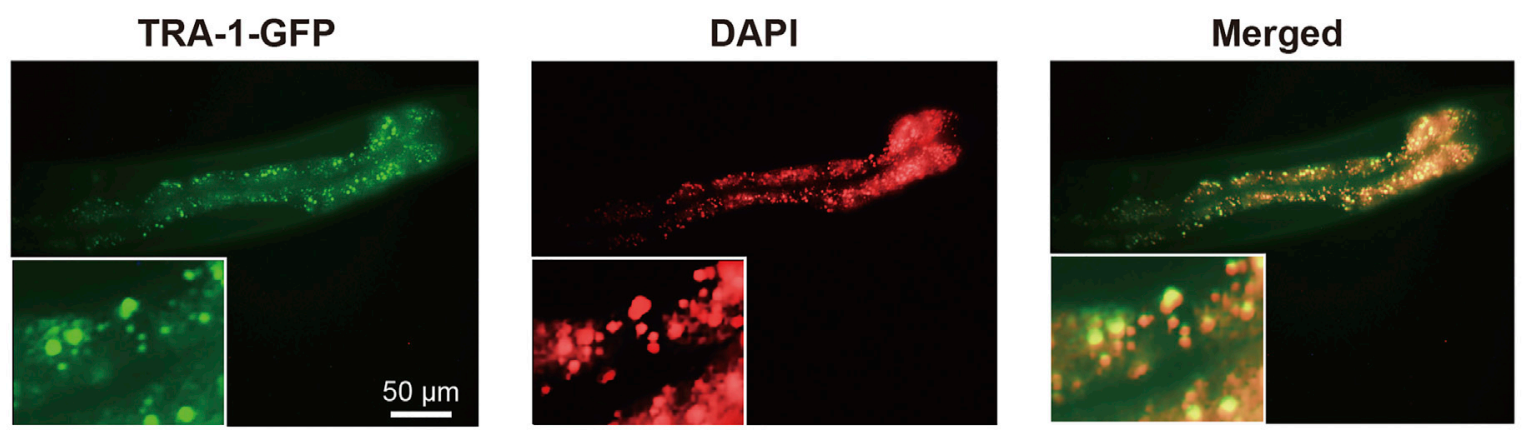

10x Magnification

D
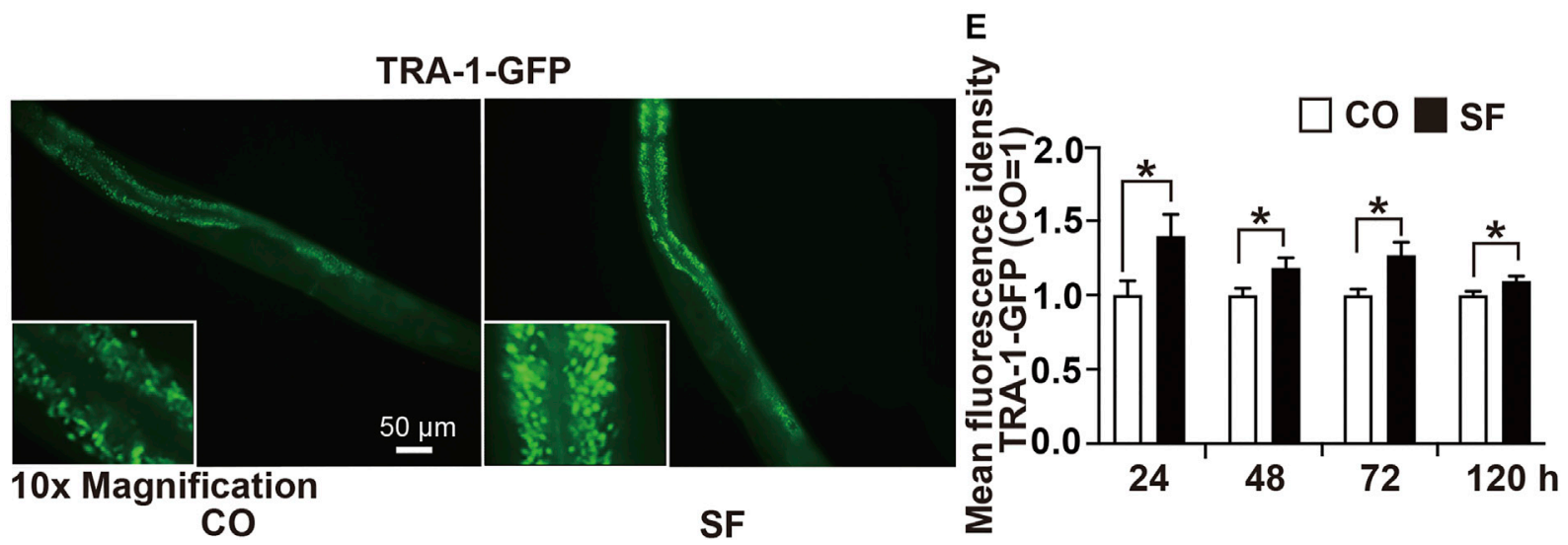

FIGURE 2 | TRA-1 expression is upregulated by sulforaphane. (A) Synchronized N2 wild-type C. elegans L4 larvae ( $n=200 /$ group) obtained $100 \mu M$ sulforaphane (SF) in their growth plates or were left untreated in the control (CO). Next, 24, 48, 72, and $120 \mathrm{~h}$ later, the total RNA was extracted, and the expression of tra-1 was detected by RT-qPCR. The expression of tra-1 is given as the fold change and is normalized to the control group, whose expression was set to 1. (B) Synchronized RA7 C. elegans worms expressing a tra-1-GFP fusion gene were treated with sulforaphane (SF) or were left untreated in the control (CO). Proteins were extracted from 200 worms per group at 24, 48, 72, or $120 \mathrm{~h}$ after sulforaphane feeding, and the expression of TRA-1 was detected by Western blot analysis using a GFP-specific antibody. Detection of tubulin expression served as a control for equal loading conditions. The protein sizes in kilodaltons (kDa) are provided (upper part). Image J was used to evaluate the pixel intensity of each band, and the expression was normalized to Tubulin. Next, the values in the sulforaphane group were related to those in the control group, which were set to 1. (C) The RA7 C. elegans strain was used to examine the expression of TRA-1-GFP by detecting green GFP fluorescence by fluorescence microscopy. The cell nuclei were counterstained with DAPI. The images were taken at $\times 400$ magnification. Insert: $\times 10$ magnification. The scale bar indicates $50 \mu \mathrm{m}$. (D) RA7 C. elegans worms ( $n=10 /$ group) were fed $100 \mu \mathrm{M}$ sulforaphane (SF) or not (CO), and 24, 48, 72, or $120 \mathrm{~h}$ later, the green spots, reflecting nuclear translocation of the TRA-1-GFP fusion protein, were detected by fluorescence microscopy. Images were taken at $\times 200$ magnification. The inserts show a $\times 10$ magnification. The scale bar indicates $50 \mu \mathrm{m}$. (E) The mean fluorescence intensities were quantified using ImageJ, and the statistical analysis is represented in the diagram. The data are shown as means \pm SEM, as evaluated by Student's t-test using SSPS $25 .{ }^{*} p<0.05,{ }^{* *} p<0.01$. 
A

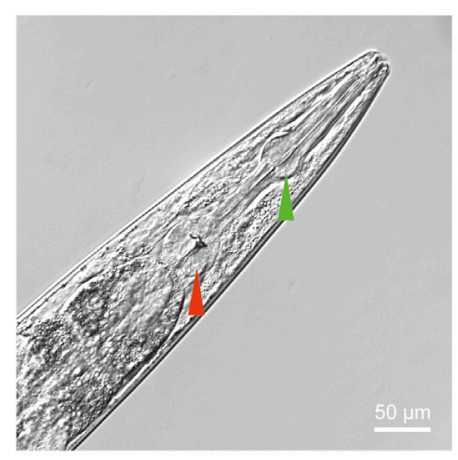

B
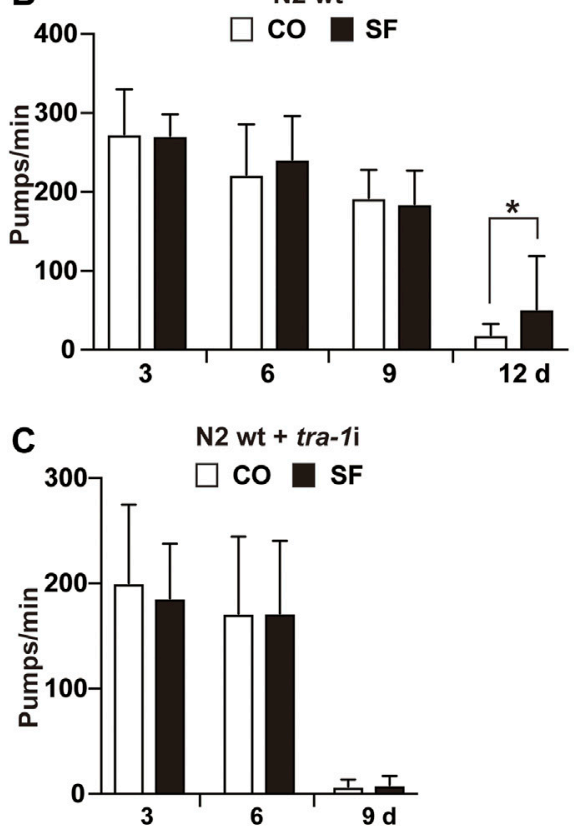

D

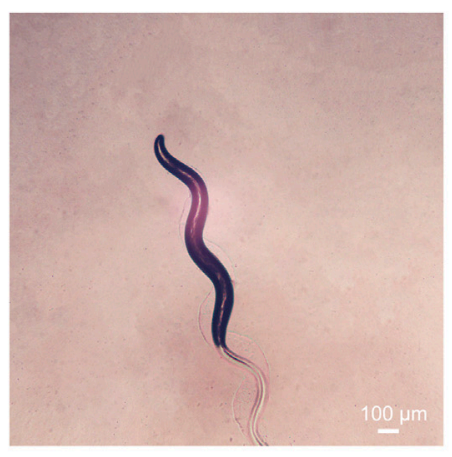

E

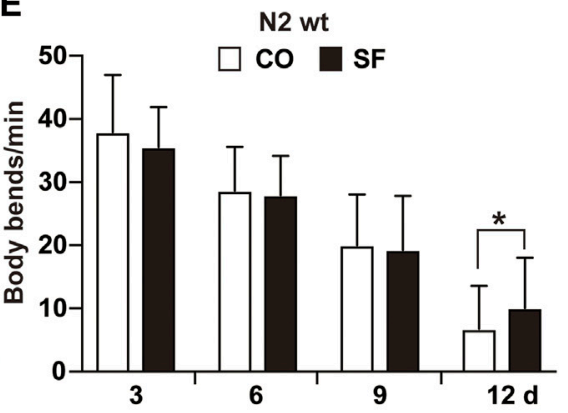

$\mathbf{F}$

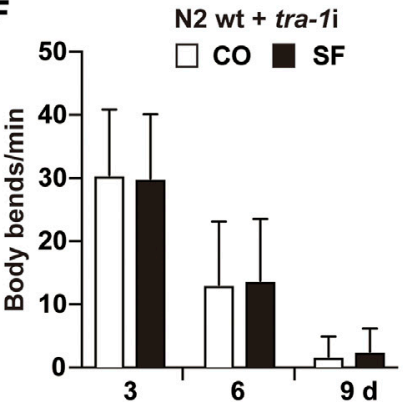

FIGURE 3|Sulforaphane increases the healthspan via TRA-1. (A) The C. elegans anterior pharynx (green arrow) and the terminal bulb (red arrow) are shown, which contract and relax synchronously during pharyngeal pumping. The scale bar indicates $50 \mu \mathrm{m}$. (B) Synchronized N2 wild-type $C$. elegans $L 4$ larvae ( $n=20 / g r o u p)$ were exposed to $100 \mu \mathrm{M}$ sulforaphane (SF) or not (CO) for 3, 6, 9, and 12 days. Afterward, pharyngeal pumping was detected under an inverted microscope. The pumping frequency per minute (Pumps/min) was calculated by evaluating the opening of the corpus, and the means, standard deviations and significance are shown in the diagram. (C) Synchronized N2 TJ356 C. elegans were fed tra-1 RNAi-transfected E. coli HT115 (DE3) bacteria in the presence of 100 MM sulforaphane (SF) or not (CO). The pharyngeal pumping rate per minute (pumps/min) was detected at Days 3, 6, and 9. For each treatment, 20 worms were examined. (D) Image of a C. elegans nematode to visualize body bends. A change in the posterior bulb direction or regular swinging of the head was considered a body bend. The scale bar indicates $100 \mu \mathrm{m}$. (E) Synchronized N2 wild-type L4 larvae ( $n=50 /$ group) received a regular diet (CO) or were fed $100 \mu M$ sulforaphane on culture plates (SF). Next, 3, 6 , 9 , or 12 days later, the mobility of $C$. elegans was detected by counting the body bends per minute (body bends/min). (F) Synchronized N2 wild-type $C$. elegans were fed tra-1 RNAitransfected E. coli HT115 (DE3) bacteria in the presence of $100 \mu \mathrm{M}$ sulforaphane (SF) or not (CO), and the body bends per minute were evaluated at the time points indicated. The data are expressed as means \pm SEM. ${ }^{\star} p<0.05,{ }^{\star *} p<0.01$.

healthspan of tra-1 RNAi-treated C. elegans worms significantly decreased at Day 9, and the worms had a lower pumping rate from the beginning and exhibited an almost quiescent state with little pharyngeal pumping, reflecting the shorter healthspan.

Next, mobility was assessed by counting the number of body bends/minute (Figure 3D). Compared with untreated wild-type worms, a significant increase from 7 to 10 body bends/minute was observed in older worms at Day 12 after sulforaphane treatment, whereas no significant difference occurred in younger worms at Days 3, 6, and 9 (Figure 3E). By contrast, sulforaphane was ineffective in C. elegans with RNAi-mediated inhibition of TRA-1 expression (Figure 3F). These results indicate that TRA-1 expression is necessary for an enhanced healthspan following sulforaphane treatment.

\section{TRA-1 Mediates Sulforaphane-Induced DAF-16 Nuclear Translocation}

To further elucidate the sulforaphane-induced signaling cascade, which mediates longevity and an increased 


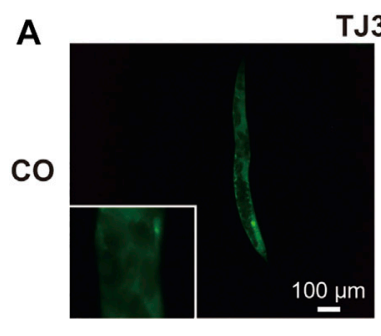

TJ356

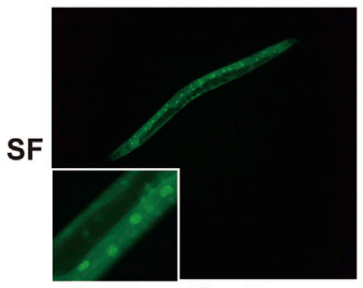

10x Magnification

C
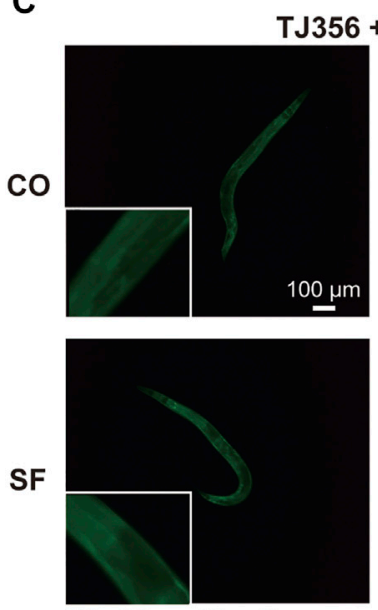

10x Magnification
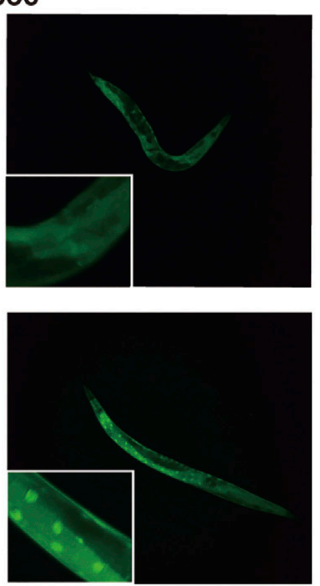

$+\operatorname{tra-1i}$
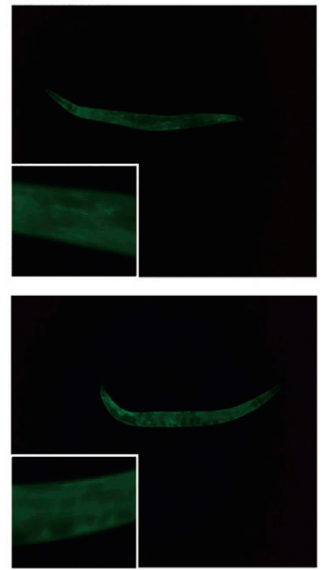

B

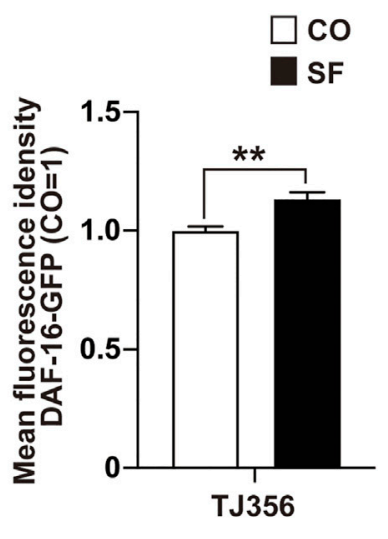

D

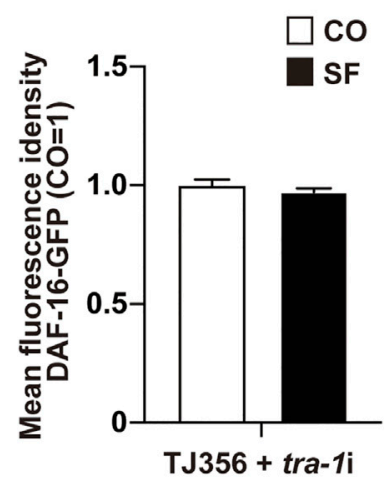

FIGURE 4 | TRA-1 mediates sulforaphane-induced DAF-16 nuclear translocation. (A) Synchronized TJ356 C. elegans L4 larvae expressing a daf-16-GFP fusion gene were fed $100 \mu \mathrm{M}$ sulforaphane (SF) or not (CO). Two days later, the nuclear translocation of DAF-16 was evaluated by detecting green fluorescent spots by fluorescence microscopy. Images were taken at $\times 100$ magnification, and the inserts had a $\times 10$ magnification. The scale bar indicates 100 m. (B) The fluorescence intensity was quantified by ImageJ, and the means, standard deviations and statistical significance are shown in the diagram. (C,D) Synchronized TJ356 L4 larval nematodes were treated and evaluated as described above. The data are shown as means \pm SEM. ${ }^{*} p<0.05,{ }^{* *} p<0.01$.

healthspan, we focused on the transcription factor DAF-16 because its binding by TRA-1 was recently detected (Hotzi et al., 2018), and DAF-16 signaling was associated with the longevity of C. elegans (Lin et al., 2018). We used the C. elegans reporter strain TJ356, which expresses a DAF-16-GFP fusion protein (Lin et al., 2001). Synchronized TJ356 L4 larvae were fed with or without sulforaphane. After $48 \mathrm{~h}$, the expression and cellular localization of the DAF-16-GFP fusion protein were examined by fluorescence microscopy. Sulforaphane-fed worms exhibited strong green fluorescent spots, indicating enhanced DAF-16 nuclear translocation, whereas the signal in control worms was lower (Figure 4A). This observation was confirmed by quantification of the fluorescence intensity using ImageJ, and the mean fluorescence intensities with standard deviations and significance are shown (Figure 4B). We confirmed these results by RNAi-mediated inhibition of TRA-1 expression in TJ356 C. elegans (Figures 4C,D). These data suggest that TRA-1 mediates sulforaphaneinduced nuclear translocation of DAF-16.

\section{DAF-16 Is Required for TRA-1-Induced Lifespan and Healthspan}

To examine the relationship between TRA-1 and DAF-16 in longevity and healthspan, we evaluated the survival of CB3844 fem-3 mutant worms that harbor a hyperactive TRA-1 protein (Hotzi et al., 2018). Compared with wildtype worms with an average lifespan of 20.5 days, the 

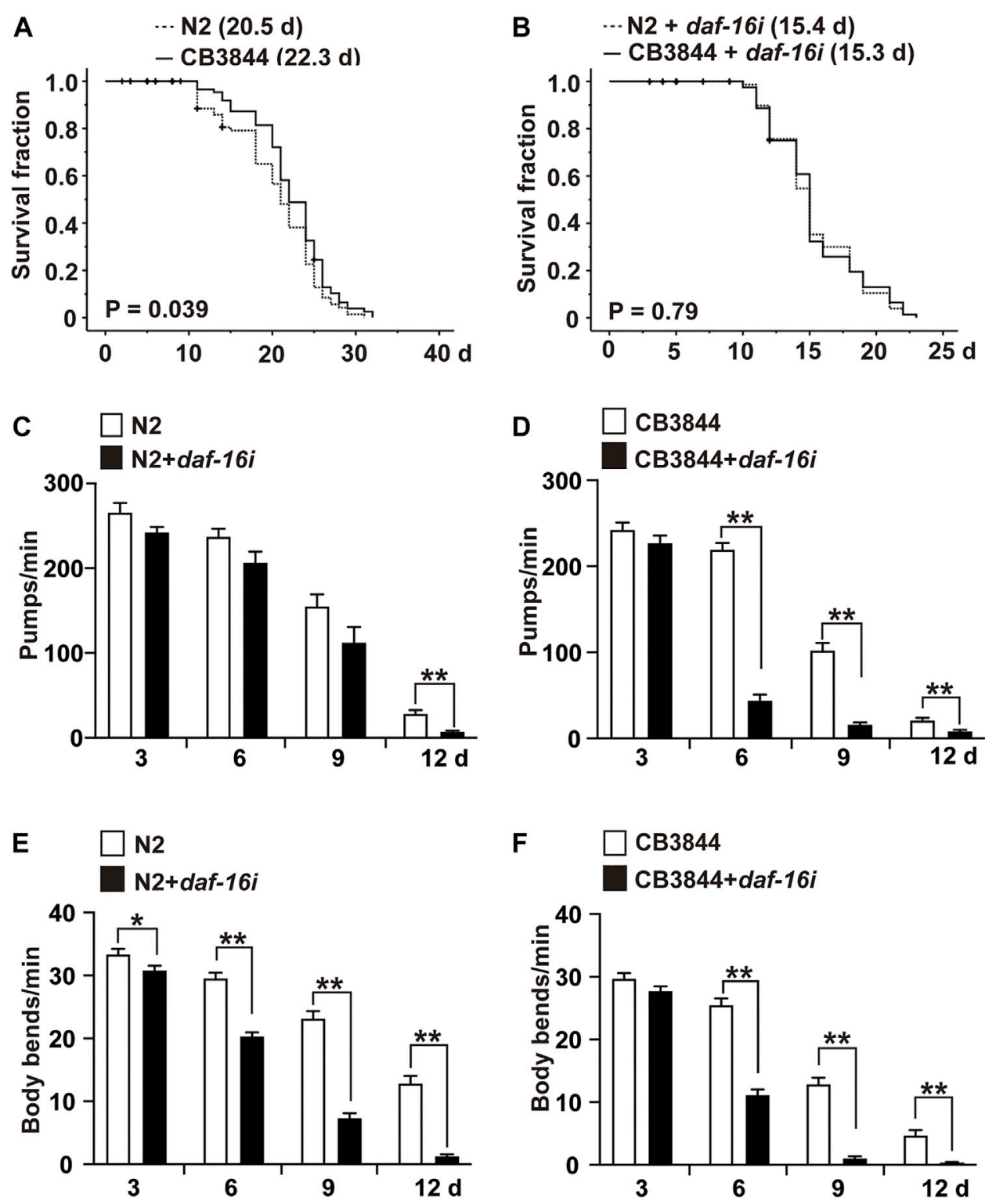

FIGURE 5 |DAF-16 is required for TRA-1-induced lifespan and healthspan. (A) Synchronized N2 wild-type (N2) and CB3844 C. elegans $L 4$ larvae ( $n=100 /$ group) were fed E. coli OP50 bacteria, followed by Kaplan-Meier analysis, as described above. (B) Synchronized N2 wild-type and CB3844 C. elegans $L 4$ larvae $(n=100 / g r o u p)$ were fed E. coli HT115 bacteria transfected with daf-16 RNAi (daf-16I), and the mean lifespan was evaluated by Kaplan-Meier analysis. (C) Synchronized N2 wild-type C. elegans worms ( $n=20 /$ group) were fed daf-16 RNAi-transduced E. coli HT115 bacteria (N2+daf-16i) or nontransduced E. coli HT115 bacteria (N2). After 3, 6, 9, and 12 days of treatment, the pharyngeal pumping rate of individual worms was detected for $60 \mathrm{~s}$. (D) Synchronized CB3844 C. elegans were fed E. coli HT115 bacteria transfected with daf-16 RNAi (CB3844+daf-16i) or untransfected E. coli HT115 bacteria (CB3844), and the pharyngeal pumping rate per minute (Pumps/min) was detected at Days 3, 6, 9, and 12. Twenty worms were examined in each group. (E) Synchronized N2 wild-type C. elegans $(n=50 /$ group) were treated as described above, and the body bends/min were counted for 60 s at Days 3, 6, 9, and 12. (F) Synchronized CB3844 C. elegans were fed as described above, and the body bends/ min were analysed.

survival of CB3844 mutant worms was 22.3 days, corresponding to a longer survival of $8.9 \%$ (Figure $\mathbf{5 A}$; Table 4). To determine whether DAF-16 is involved in TRA-1-mediated life prolongation, we inhibited daf-16 by RNAi in wild-type and CB3844 mutant worms and performed Kaplan-Meier analysis. With inhibited daf-16 expression, the CB3844 worms did not survive longer than the wild-type worms (Figure 5B), indicating that DAF-16 is required for TRA-1-induced longevity.

Finally, we assessed whether DAF-16 may be required for the previously observed TRA-1-mediated prolonged healthspan, the expression of daf-16 was inhibited by feeding E. coli HT115 bacteria transfected with daf-16 RNAi, which resulted in a significant inhibition of daf-16 RNA levels in N2 wild-type 
TABLE 4 | Lifespan of $C$. elegans strains.

\begin{tabular}{|c|c|c|c|c|c|c|}
\hline Temperature $\left({ }^{\circ} \mathrm{C}\right)$ & Fig. No. & Exp. No. & $\begin{array}{l}\text { C. elegans } \\
\text { strains }\end{array}$ & $\begin{array}{l}\text { Mean lifespan } \\
\text { 土SEM (days) }\end{array}$ & $\begin{array}{l}\text { \%, *mean } \\
\text { increase }\end{array}$ & $p$ Value \\
\hline \multirow[t]{6}{*}{20} & $5 \mathrm{~A}$ & 1 & N2 & $19.72 \pm 0.40$ & 3.6 & 0.037 \\
\hline & & - & CB3844 & $20.42 \pm 0.48$ & & \\
\hline & & 2 & N2 & $20.48 \pm 0.60$ & 8.9 & 0.039 \\
\hline & & - & CB3844 & $22.29 \pm 0.50$ & & \\
\hline & & 3 & $\mathrm{~N} 2$ & $21.74 \pm 0.46$ & 7.0 & 0.031 \\
\hline & & - & CB3844 & $23.27 \pm 0.54$ & & \\
\hline \multirow[t]{6}{*}{20} & $5 B$ & 1 & N2 (daf16i) & $15.35 \pm 0.36$ & - & 0.793 \\
\hline & & - & CB3844(daf16i) & $15.34 \pm 0.38$ & & \\
\hline & & 2 & N2 (daf16i) & $15.55 \pm 0.37$ & - & 0.710 \\
\hline & & - & CB3844(daf16i) & $15.40 \pm 0.38$ & & \\
\hline & & 3 & N2 (daf16i) & $16.24 \pm 0.38$ & - & 0.828 \\
\hline & & - & CB3844(daf16i) & $16.19 \pm 0.39$ & & \\
\hline
\end{tabular}

Mean lifespan: Corresponds to the mean lifespan as measured in the present study. The mean lifespan values were calculated by the log-rank (Kaplan-Meier) statistical test. p values less than 0.05 were considered statistically significant, whereas statistical significance was not calculated (-) when $\mathrm{p}$ values were $>0.05$. All statistical evaluations were calculated using SPSS 25. Each experiment included $100 \mathrm{C}$. elegans nematodes. SEM: standard error of the mean.

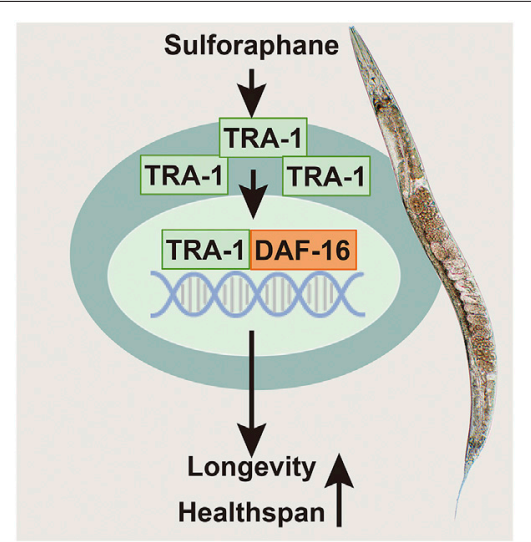

FIGURE 6 | Scheme of sulforaphane-promoted lifespan and healthspan by inducing TRA-1 and DAF-16 nuclear translocation. Sulforaphane induces enhanced protein levels of the TRA-1 terminal transcription factor of the $C$. elegans sex-determination pathway. TRA-1 translocates to the nucleus, where it binds to DAF-16, which is the main target of the insulin/insulin-like growth factor signaling pathway, plays a fundamental role in lifespan, metabolism and stress responses and is related to the mobility and food intake of $C$. elegans. We assume that this scenario is responsible for the observed sulforaphane-mediated extended lifespan and improved healthspan of $C$. elegans.

and CB3884 worms, as examined by RT-qPCR $48 \mathrm{~h}$ later (Supplementary Figure S1). The examination of pharyngeal pumping demonstrated that the pumping frequency significantly decreased from 28 to 7 pumps/minute at Day 12 in older wild-type worms, whereas no difference was observed in younger worms at Days 3, 6, and 9 (Figure 5C). This effect was even more pronounced in the C. elegans CB3844 strain following RNAi-mediated inhibition of daf-16 because the pumping frequency already decreased not only at Day 12 but also at Days 6 and 9 (Figure 5D). Likewise, the inhibition of daf-16 expression by RNAi in wild-type worms significantly reduced the body bends/minute at all time points examined (Figure 5E). The effects were even more pronounced following RNAi-mediated inhibition of $d a f-16$ in CB3844 worms (Figure 5F), as expected. These results imply that DAF-16 is a crucial downstream effector in TRA-1-mediated increased longevity and healthspan in $C$. elegans (Figure 6), although this conclusion requires further confirmation.

\section{DISCUSSION}

The present study hypothesized that the bioactive agent sulforaphane prolongs the lifespan and healthspan of $C$. elegans by inducing TRA-1 signaling, which mediates its effects by the downstream transcription factor DAF-16. Using C. elegans strains with hyperactive TRA-1 or loss-of-function mutations in tra-1 and RNAi-mediated inhibition of tra-1 or daf16 in wild-type $C$. elegans, we demonstrate that sulforaphane mediates its effects by inducing TRA-1 and downstream DAF-16 signaling. This finding was validated using Kaplan-Meier survival analysis, healthspan assays of pharyngeal pumping and the detection of body bending frequency.

According to our results, sulforaphane increased the average lifespan and significantly promoted the healthspan in the mid-life period of $C$. elegans at approximately 8-12 days of age, confirming our recent data, that demonstrated the regulation of DAF-16/FOXO signaling by sulforaphane and thereby an extension of the lifespan (Qi et al., 2021). However, it remained unclear by which upstream step sulforaphane leads to modification of DAF-16 signaling. Our new findings in the present study demonstrate that sulforaphane induced the expression of the tra-1 gene that in turn regulates DAF-16 signaling. These findings are consistent with previous studies showing a benefit of sulforaphane in cancer chemoprevention and human health, such as anti-inflammatory and anti-atopic allergic responses (Brown et al., 2015; Bayat Mokhtari et al., 2018; Sidhaye et al., 2019). Conversely, we observed that the loss of tra-1 expression or its function shortened the lifespan and decreased 
the healthspan, which could not be reversed by sulforaphane. Therefore, we assume that TRA-1 is a crucial modulator of sulforaphane-promoted longevity and healthspan in C. elegans. This assumption was confirmed by Western blot analysis, which demonstrated upregulated TRA-1 protein expression by sulforaphane. Additionally, we found that the average lifespan of C. elegans with hyperactive TRA-1, because of a fem-3 mutation, increased by $8.9 \%$. Our data agree with those of a previous study implying a longer survival of hermaphroditic $C$. elegans worms with a higher TRA-1 expression level than that of male worms (Johnson and Wood, 1982). By contrast, we did not detect sulforaphane-induced upregulation of tra-1 RNA levels. This observation might be explained by the data of a recent report demonstrating that the regulation of tra-1 occurs posttranscriptionally in male and hermaphroditic C. elegans nematodes (Zarkower and Hodgkin, 1992).

Furthermore, we observed that sulforaphane promoted the nuclear translocation of TRA-1 and its downstream target DAF16. Naturally, the sulforaphane-induced translocation of DAF-16 was prevented in tra-1 (-) mutant C. elegans nematodes and following RNAi-mediated tra-1 inhibition in TJ356 worms. Additionally, we observed that food intake and mobility significantly decreased in C. elegans worms with dysfunctional daf-16. This finding is not surprising because DAF-16 is the main target of the insulin/insulin-like growth factor signaling pathway (Murphy and $\mathrm{Hu}, 2013$ ), plays a fundamental role in lifespan, metabolism and stress responses and is related to the mobility and food intake of C. elegans (Thomas, 1999; Ryu et al., 2016; Lin et al., 2018; Wang et al., 2019; Aghayeva et al., 2021). These facts may explain our observation of decreased pharyngeal pumping and body bending rates in TRA-1 hyperactive C. elegans mutant worms after RNAi-mediated daf-16 inhibition. The fact that sulforaphane fails to promote longevity in absence of tra- 1 but nevertheless does not significantly upregulate tra-1 mRNA expression is indeed intriguing. Therefore, it may be plausible that mRNA expression of tra-1 is required for sulforaphane to exert its effect. However, we cannot exclude that tra-1 may very well upregulate another unidentified mediator beside daf-16.

Despite our promising findings, there are still limitations of our study. For example, we only performed Kaplan-Meier survival analysis and healthspan assays to investigate the interaction of TRA-1 and DAF-16, and we did not perform e.g. pull-down assays to demonstrate a direct TRA-1-DAF-16 interaction. However, a recent study described two conserved TRA-1 binding sites in the daf-16 promoter (Hotzi et al., 2018), suggesting that the binding of TRA-1 to DAF-16 is necessary for the sulforaphane-induced nuclear translocation of DAF-16. These findings prompted us to speculate that DAF-16 is a downstream target in TRA-1-induced heathy aging in $C$. elegans. However, this suggestion still requires further confirmation.

Finally, we even suspect that our data in C. elegans may be of relevance to human health, because many epidemiological and pharmacological studies have shown that sulforaphane consumption is associated with a reduced risk of disease in humans. Recent data have demonstrated the effects of sulforaphane on metabolism-related disorders and concluded that sulforaphane improves glycemic control in type 2 diabetes and ameliorates the changes associated with diabetic nephropathy (Wu et al., 2015; Axelsson et al., 2017). Furthermore, the regulation of lifespan by the insulin/insulinlike growth factor signaling pathway is highly conserved in nematodes and humans (Tazearslan et al., 2011). Interestingly, variants of FOXO3A-the mammalian DAF-16 homolog-are more frequent in centenarians than in 90-year-olds, as reported in a German cohort study (Flachsbart et al., 2009). These previous studies in humans and our results obtained in the C. elegans model prompt us to speculate that sulforaphane might extend the lifespan also in humans. However, an open question is how much sulforaphane-e.g., in the form of broccoli or its sprouts-should be ingested by humans to cause antiaging or anticancer effects. Some reports, including a prospective study, have observed a reduced risk of aggressive prostate cancer by a high intake of more than one serving of sulforaphane-rich broccoli or cauliflower per week (Kirsh et al., 2007). A recent pilot patient study in advanced pancreatic cancer used a daily intake of $90 \mathrm{mg}$ of sulforaphane in the form of broccoli sprouts and observed positive, although nonsignificant, effects on the survival of cancer patients (Lozanovski et al., 2019).

\section{CONCLUSION}

Our study demonstrates that sulforaphane initiates TRA-1 signaling via its downstream target DAF-16 to prolong the lifespan and healthspan of $C$. elegans. These data provide a promising hint regarding the suitability of sulforaphane as a novel anti-aging drug and tra- 1 as a novel target in anti-aging and disease prevention strategies.

\section{DATA AVAILABILITY STATEMENT}

The original contributions presented in the study are included in the article/Supplementary Material, further inquiries can be directed to the corresponding author.

\section{AUTHOR CONTRIBUTIONS}

$\mathrm{IH}, \mathrm{HJ}$, and ZQ: Concept and design. HJ, ZQ, and ML: Development of methodology. HJ, DS: Acquisition of data. HJ, ZQ, and LL: Analysis and interpretation of data. IH, HJ: Writing of the manuscript. YL and BY: Interpretation of data. MS and JG: Technical Support. All authors: Review or revision of the manuscript.

\section{FUNDING}

This study received funding from the German Research Council (DFG HE 3186/15-1), Mr. Julius Burmeister-BIMAG Baumaschinen $\mathrm{GmbH}$, Heidelberger Stiftung Chirurgie, Dietmar Hopp-Stiftung, Klaus Tschira Stiftung and Hanns A. 
Pielenz-Stiftung. These funders were not involved in the study design, collection, analysis, interpretation of data, the writing of this article or the decision to submit it for publication.

\section{ACKNOWLEDGMENTS}

We thank the CGC, which is funded by the NIH Office of Research Infrastructure Programs (P40 OD010440), for

\section{REFERENCES}

Aghayeva, U., Bhattacharya, A., Sural, S., Jaeger, E., Churgin, M., Fang-Yen, C., et al. (2021). DAF-16/FoxO and DAF-12/VDR Control Cellular Plasticity Both Cell-Autonomously and via Interorgan Signaling. Plos Biol. 19, e3001204. doi:10.1371/journal.pbio.3001204

Ashrafi, K., Chang, F. Y., Watts, J. L., Fraser, A. G., Kamath, R. S., Ahringer, J., et al. (2003). Genome-wide RNAi Analysis of Caenorhabditis elegans Fat Regulatory Genes. Nature 421, 268-272. doi:10.1038/nature01279

Axelsson, A. S., Tubbs, E., Mecham, B., Chacko, S., Nenonen, H. A., Tang, Y., et al. (2017). Sulforaphane Reduces Hepatic Glucose Production and Improves Glucose Control in Patients with Type 2 Diabetes. Sci. Transl Med. 9, eaah4477. doi:10.1126/scitranslmed.aah4477

Bayat Mokhtari, R., Baluch, N., Homayouni, T. S., Morgatskaya, E., Kumar, S., Kazemi, P., et al. (2018). The Role of Sulforaphane in Cancer Chemoprevention and Health Benefits: a Mini-Review. J. Cel Commun. Signal. 12, 91-101. doi:10.1007/s12079-017-0401-y

Brenner, S. (1974). The Genetics of Caenorhabditis elegans. Genetics 77, 71-94. doi:10.1093/genetics/77.1.71

Briscoe, J., and Thérond, P. P. (2013). The Mechanisms of Hedgehog Signalling and its Roles in Development and Disease. Nat. Rev. Mol. Cel Biol. 14, 416-429. doi: $10.1038 / \mathrm{nrm} 3598$

Brown, R. H., Reynolds, C., Brooker, A., Talalay, P., and Fahey, J. W. (2015). Sulforaphane Improves the Bronchoprotective Response in Asthmatics through Nrf2-Mediated Gene Pathways. Respir. Res. 16, 106. doi:10.1186/s12931-015-0253-z

Chan, J. M., Wang, F., and Holly, E. A. (2005). Vegetable and Fruit Intake and Pancreatic Cancer in a Population-Based Case-Control Study in the San Francisco bay Area. Cancer Epidemiol. Biomarkers Prev. 14, 2093-2097. doi:10.1158/1055-9965.epi-05-0226

Chen, J., Zhang, J., Xiang, Y., Xiang, L., Liu, Y., He, X., et al. (2016). Extracts of Tsai Tai (Brassica Chinensis): Enhanced Antioxidant Activity and Anti-aging Effects Both In Vitro and in Caenorhabditis elegans. Food Funct. 7, 943-952. doi:10.1039/c5fo01241d

Cho, A., Park, S.-R., Kim, S.-R., Nam, S., Lim, S., Park, C. H., et al. (2019). An Endogenous Anti-aging Factor, Sonic Hedgehog, Suppresses Endometrial Stem Cell Aging through SERPINB2. Mol. Ther. 27, 1286-1298. doi:10.1016/ j.ymthe.2019.04.019

Collins, J. J., Huang, C., Hughes, S., and Kornfeld, K. (2008). The Measurement and Analysis of Age-Related Changes in Caenorhabditis elegans. Louis: WormBook, 1-21.

Consortium, C. E. S. (1998). Genome Sequence of the Nematode C. elegans: a Platform for Investigating Biology. Science 282, 2012-2018. doi:10.1126/ science.282.5396.2012

Coquenlorge, S., Yin, W.-C., Yung, T., Pan, J., Zhang, X., Mo, R., et al. (2019). GLI2 Modulated by SUFU and SPOP Induces Intestinal Stem Cell Niche Signals in Development and Tumorigenesis. Cel Rep. 27, 3006-3018. doi:10.1016/ j.celrep.2019.05.016

Corsi, A. K., Wightman, B., and Chalfie, M. (2015). A Transparent Window into Biology: A Primer on Caenorhabditis elegans. Genetics 200, 387-407. doi:10.1534/genetics.115.176099

Crimmins, E. M. (2015). Lifespan and Healthspan: Past, Present, and Promise. Geront 55, 901-911. doi:10.1093/geront/gnv130

Ellis, R., and Schedl, T. (2007). Sex Determination in the Germ Line. Stratford: WormBook, 1-13. doi:10.1895/wormbook.1.82.2 providing $C$. elegans strains. We are grateful to our lab colleagues X. F. An and K. T. Wang for helpful discussions.

\section{SUPPLEMENTARY MATERIAL}

The Supplementary Material for this article can be found online at: https://www.frontiersin.org/articles/10.3389/fcell.2021.784999/ full\#supplementary-material

Finkel, T. (2015). The Metabolic Regulation of Aging. Nat. Med. 21, 1416-1423. doi: $10.1038 / \mathrm{nm} .3998$

Flachsbart, F., Caliebe, A., Kleindorp, R., Blanché, H., von Eller-Eberstein, H., Nikolaus, S., et al. (2009). Association ofFOXO3Avariation with Human Longevity Confirmed in German Centenarians. Pnas 106, 2700-2705. doi:10.1073/pnas.0809594106

Grote, P., and Conradt, B. (2006). The PLZF-like Protein TRA-4 Cooperates with the Gli-like Transcription Factor TRA-1 to Promote Female Development in C. elegans. Develop. Cel. 11, 561-573. doi:10.1016/j.devcel.2006.07.015

Grünwald, S., Stellzig, J., Adam, I. V., Weber, K., Binger, S., Boll, M., et al. (2013). Longevity in the Red Flour Beetle Tribolium castaneum Is Enhanced by Broccoli and Depends on Nrf-2, Jnk-1 and Foxo-1 Homologous Genes. Genes Nutr. 8, 439-448. doi:10.1007/s12263-012-0330-6

Heinen, M. M., Verhage, B. A. J., Goldbohm, R. A., and van den Brandt, P. A. (2012). Intake of Vegetables, Fruits, Carotenoids and Vitamins C and E and Pancreatic Cancer Risk in The Netherlands Cohort Study. Int. J. Cancer 130, 147-158. doi:10.1002/ijc.25989

Herr, I., and Büchler, M. W. (2010). Dietary Constituents of Broccoli and Other Cruciferous Vegetables: Implications for Prevention and Therapy of Cancer. Cancer Treat. Rev. 36, 377-383. doi:10.1016/j.ctrv.2010.01.002

Hodgkin, J. (1987). A Genetic Analysis of the Sex-Determining Gene, Tra-1, in the Nematode Caenorhabditis elegans. Genes Dev. 1, 731-745. doi:10.1101/gad.1.7.731

Hodgkin, J. (1986). Sex Determination in the Nematode C. elegans: Analysis of Tra3 Suppressors and Characterization of Fem Genes. Genetics 114, 15-52. doi:10.1093/genetics/114.1.15

Hotzi, B., Kosztelnik, M., Hargitai, B., Takács-Vellai, K., Barna, J., Bördén, K., et al. (2018). Sex-specific Regulation of Aging in Caenorhabditis elegans. Aging Cell 17, e12724. doi:10.1111/acel.12724

Hou, Y., Dan, X., Babbar, M., Wei, Y., Hasselbalch, S. G., Croteau, D. L., et al. (2019). Ageing as a Risk Factor for Neurodegenerative Disease. Nat. Rev. Neurol. 15, 565-581. doi:10.1038/s41582-019-0244-7

Johnson, T. E., and Wood, W. B. (1982). Genetic Analysis of Life-Span in Caenorhabditis elegans. Proc. Natl. Acad. Sci. 79, 6603-6607. doi:10.1073/ pnas.79.21.6603

Kaletta, T., and Hengartner, M. O. (2006). Finding Function in Novel Targets: $C$. elegans as a Model Organism. Nat. Rev. Drug Discov. 5, 387-399. doi:10.1038/ $\operatorname{nrd} 2031$

Kamath, R. S., Martinez-Campos, M., Zipperlen, P., Fraser, A. G., and Ahringer, J. (2001). Effectiveness of Specific RNA-Mediated Interference through Ingested Double-Stranded RNA in Caenorhabditis elegans. Genome Biol. 2, RESEARCH0002. doi:10.1186/gb-2000-2-1-research0002

Ke, T., Santamaría, A., Tinkov, A. A., Bornhorst, J., and Aschner, M. (2020). Generating Bacterial Foods in Toxicology Studies with Caenorhabditis elegans. Curr. Protoc. Toxicol. 84, e94. doi:10.1002/cptx.94

Kirsh, V. A., Peters, U., Mayne, S. T., Subar, A. F., Chatterjee, N., Johnson, C. C., et al. (2007). Prospective Study of Fruit and Vegetable Intake and Risk of Prostate Cancer. JNCI J. Natl. Cancer Inst. 99, 1200-1209. doi:10.1093/jnci/ djm065

Kutnyánszky, V., Hargitai, B., Hotzi, B., Kosztelnik, M., Ortutay, C., Kovács, T., et al. (2020). Sex-specific Regulation of Neuronal Functions in Caenorhabditis elegans: the Sex-Determining Protein TRA-1 Represses goa-1/Ga(i/o). Mol. Genet. Genomics 295, 357-371. doi:10.1007/s00438-019-01625-0

Lee, R. Y. N., Hench, J., and Ruvkun, G. (2001). Regulation of C. elegans DAF-16 and its Human Ortholog FKHRL1 by the Daf-2 Insulin-like Signaling Pathway. Curr. Biol. 11, 1950-1957. doi:10.1016/s0960-9822(01)00595-4 
Li, S.-H., Fu, J., Watkins, D. N., Srivastava, R. K., and Shankar, S. (2013). Sulforaphane Regulates Self-Renewal of Pancreatic Cancer Stem Cells through the Modulation of Sonic Hedgehog-GLI Pathway. Mol. Cel. Biochem. 373, 217-227. doi:10.1007/s11010-012-1493-6

Lin, K., Dorman, J. B., Rodan, A., and Kenyon, C. (1997). daf-16 : An HNF-3/forkhead Family Member that Can Function to Double the Life-Span of Caenorhabditis elegans. Science 278, 1319-1322. doi:10.1126/science.278.5341.1319

Lin, K., Hsin, H., Libina, N., and Kenyon, C. (2001). Regulation of the Caenorhabditis elegans Longevity Protein DAF-16 by insulin/IGF-1 and Germline Signaling. Nat. Genet. 28, 139-145. doi:10.1038/88850

Lin, X.-X., Sen, I., Janssens, G. E., Zhou, X., Fonslow, B. R., Edgar, D., et al. (2018). DAF-16/FOXO and HLH-30/TFEB Function as Combinatorial Transcription Factors to Promote Stress Resistance and Longevity. Nat. Commun. 9, 4400. doi:10.1038/s41467-018-06624-0

Lozanovski, V. J., Polychronidis, G., Gross, W., Gharabaghi, N., Mehrabi, A., Hackert, T., et al. (2019). Broccoli Sprout Supplementation in Patients with Advanced Pancreatic Cancer Is Difficult Despite Positive Effects-Results from the POUDER Pilot Study. Invest. New Drugs 38, 776-784. doi:10.1007/s10637019-00826-Z

Mathies, L. D., Schvarzstein, M., Morphy, K. M., Blelloch, R., Spence, A. M., and Kimble, J. (2004). TRA-1/GLI Controls Development of Somatic Gonadal Precursors in C. elegans. Development 131, 4333-4343. doi:10.1242/dev.01288

Mergoud Dit Lamarche, A., Molin, L., Pierson, L., Mariol, M. C., Bessereau, J. L., Gieseler, K., et al. (2018). UNC-120/SRF Independently Controls Muscle Aging and Lifespan in Caenorhabditis elegans. Aging Cell 17, e12713. doi:10.1111/ acel.12713

Murphy, C. T., and Hu, P. J. (2013). Insulin/insulin-like Growth Factor Signaling in C. elegans. Princeton: WormBook, 1-43. doi:10.1895/wormbook.1.164.1

Neoptolemos, J. P., Kleeff, J., Michl, P., Costello, E., Greenhalf, W., and Palmer, D. H. (2018). Therapeutic Developments in Pancreatic Cancer: Current and Future Perspectives. Nat. Rev. Gastroenterol. Hepatol. 15, 333-348. doi:10.1038/s41575-018-0005-x

Niccoli, T., and Partridge, L. (2012). Ageing as a Risk Factor for Disease. Curr. Biol. 22, R741-R752. doi:10.1016/j.cub.2012.07.024

Olshansky, S. J. (2018). From Lifespan to Healthspan. JAMA 320, 1323-1324. doi:10.1001/jama.2018.12621

Pires-daSilva, A., and Sommer, R. J. (2004). Conservation of the Global Sex Determination Gene Tra-1 in Distantly Related Nematodes. Genes Dev. 18, 1198-1208. doi:10.1101/gad.293504

Pramanik, K. C., Fofaria, N. M., Gupta, P., and Srivastava, S. K. (2014). CBPmediated FOXO-1 Acetylation Inhibits Pancreatic Tumor Growth by Targeting SirT. Mol. Cancer Ther. 13, 687-698. doi:10.1158/1535-7163.mct-13-0863

Qi, Z., Ji, H., Le, M., Li, H., Wieland, A., Bauer, S., et al. (2021). Sulforaphane Promotes C. elegans Longevity and Healthspan via DAF-16/DAF-2 insulin/ IGF-1 Signaling. Aging 13, 1649-1670. doi:10.18632/aging.202512

Raizen, D., Song, B. M., Trojanowski, N., and You, Y. J. (2012). Methods for Measuring Pharyngeal Behaviors. Philadelphia: WormBook, 1-13. doi:10.1895/wormbook.1.154.1

Roy, S. K., Srivastava, R. K., and Shankar, S. (2010). Inhibition of PI3K/AKT and MAPK/ERK Pathways Causes Activation of FOXO Transcription Factor, Leading to Cell Cycle Arrest and Apoptosis in Pancreatic Cancer. Jms 5, 10. doi:10.1186/1750-2187-5-10

Ryu, D., Mouchiroud, L., Andreux, P. A., Katsyuba, E., Moullan, N., Nicolet-ditFélix, A. A., et al. (2016). Urolithin A Induces Mitophagy and Prolongs Lifespan in C. elegans and Increases Muscle Function in Rodents. Nat. Med. 22, 879-888. doi:10.1038/nm.4132

Santín-Márquez, R., Alarcón-Aguilar, A., López-Diazguerrero, N. E., Chondrogianni, N., and Königsberg, M. (2019). Sulforaphane - Role in Aging and Neurodegeneration. Geroscience 41, 655-670. doi:10.1007/s11357-019-00061-7

Schvarzstein, M., and Spence, A. M. (2006). The C. elegans Sex-Determining GLI Protein TRA-1A Is Regulated by Sex-specific Proteolysis. Develop. Cel 11, 733-740. doi:10.1016/j.devcel.2006.09.017

Sedrak, M. S., Freedman, R. A., Cohen, H. J., Muss, H. B., Jatoi, A., Klepin, H. D., et al. (2021). Older Adult Participation in Cancer Clinical Trials: A Systematic Review of Barriers and Interventions. CA A. Cancer J. Clin. 71, 78-92. doi:10.3322/caac. 21638

Shen, P., Yue, Y., and Park, Y. (2018). A Living Model for Obesity and Aging Research:Caenorhabditis elegans. Crit. Rev. Food Sci. Nutr. 58, 741-754. doi:10.1080/10408398.2016.1220914
Sidhaye, V. K., Holbrook, J. T., Burke, A., Sudini, K. R., Sethi, S., Criner, G. J., et al. (2019). Compartmentalization of Anti-oxidant and Anti-inflammatory Gene Expression in Current and Former Smokers with COPD. Respir. Res. 20, 190. doi:10.1186/s12931-019-1164-1

Siegel, R. L., Miller, K. D., Fuchs, H. E., and Jemal, A. (2021). Cancer Statistics, 2021. CA A. Cancer J. Clin. 71, 7-33. doi:10.3322/caac.21654

Sohal, D. P. S., Mangu, P. B., Khorana, A. A., Shah, M. A., Philip, P. A., O’Reilly, E. M., et al. (2016). Metastatic Pancreatic Cancer: American Society of Clinical Oncology Clinical Practice Guideline. Jco 34, 2784-2796. doi:10.1200/ jco.2016.67.1412

Starostina, N. G., Lim, J.-m., Schvarzstein, M., Wells, L., Spence, A. M., and Kipreos, E. T. (2007). A CUL-2 Ubiquitin Ligase Containing Three FEM Proteins Degrades TRA-1 to Regulate C. elegans Sex Determination. Develop. Cel 13, 127-139. doi:10.1016/j.devcel.2007.05.008

Stiernagle, T. (2006). Maintenance of C. elegans. Minneapolis: WormBook, 1-11. doi:10.1895/wormbook.1.101.1

Szabó, E., Hargitai, B., Regős, Á., Tihanyi, B., Barna, J., Borsos, É., et al. (2009). TRA-1/GLI Controls the Expression of the Hox Gene Lin-39 during C. elegans Vulval Development. Develop. Biol. 330, 339-348. doi:10.1016/ j.ydbio.2009.04.005

Tazearslan, C., Huang, J., Barzilai, N., and Suh, Y. (2011). Impaired IGF1R Signaling in Cells Expressing Longevity-Associated Human IGF1R Alleles. Aging Cell 10, 551-554. doi:10.1111/j.1474-9726.2011.00697.x

Thomas, J. H. (1999). The Effects of Sensory Deprivation. Nature 402, 740-741. doi: $10.1038 / 45422$

Wang, H., Webster, P., Chen, L., and Fisher, A. L. (2019). Cell-autonomous and Non-autonomous Roles of Daf-16 in Muscle Function and Mitochondrial Capacity in Aging C. elegans. Aging 11, 2295-2311. doi:10.18632/aging.101914

Watson, E., MacNeil, L. T., Arda, H. E., Zhu, L. J., and Walhout, A. J. M. (2013). Integration of Metabolic and Gene Regulatory Networks Modulates the C. elegans Dietary Response. Cell 153, 253-266. doi:10.1016/j.cell.2013.02.050

World Health Organization (2018). Ageing and health. who. Available at: int/ newsroom/fact-sheets/detail/ageing-andhealth.

Wu, H., Kong, L., Cheng, Y., Zhang, Z., Wang, Y., Luo, M., et al. (2015). Metallothionein Plays a Prominent Role in the Prevention of Diabetic Nephropathy by Sulforaphane via Up-Regulation of Nrf2. Free Radic. Biol. Med. 89, 431-442. doi:10.1016/j.freeradbiomed.2015.08.009

Wueseke, O., Bunkenborg, J., Hein, M. Y., Zinke, A., Viscardi, V., Woodruff, J. B., et al. (2014). The Caenorhabditis elegans Pericentriolar Material Components SPD-2 and SPD-5 Are Monomeric in the Cytoplasm before Incorporation into the PCM Matrix. MBoC 25, 2984-2992. doi:10.1091/mbc.e13-09-0514

Zarkower, D., De Bono, M., Aronoff, R., and Hodgkin, J. (1994). Regulatory Rearrangements Andsmg-Sensitive Allels of theC. Elegans Sex-Determining Genetra-1. Dev. Genet. 15, 240-250. doi:10.1002/dvg.1020150306

Zarkower, D., and Hodgkin, J. (1992). Molecular Analysis of the C. elegans SexDetermining Gene Tra-1: a Gene Encoding Two Zinc finger Proteins. Cell 70, 237-249. doi:10.1016/0092-8674(92)90099-x

Zhang, S., Li, F., Zhou, T., Wang, G., and Li, Z. (2020). Caenorhabditis elegans as a Useful Model for Studying Aging Mutations. Front. Endocrinol. 11, 554994. doi:10.3389/fendo.2020.554994

Conflict of Interest: The authors declare that the research was conducted in the absence of any commercial or financial relationships that could be construed as a potential conflict of interest.

Publisher's Note: All claims expressed in this article are solely those of the authors and do not necessarily represent those of their affiliated organizations, or those of the publisher, the editors and the reviewers. Any product that may be evaluated in this article, or claim that may be made by its manufacturer, is not guaranteed or endorsed by the publisher.

Copyright (c) 2021 Ji, Qi, Schrapel, Le, Luo, Yan, Gladkich, Schaefer, Liu and Herr. This is an open-access article distributed under the terms of the Creative Commons Attribution License (CC BY). The use, distribution or reproduction in other forums is permitted, provided the original author(s) and the copyright owner(s) are credited and that the original publication in this journal is cited, in accordance with accepted academic practice. No use, distribution or reproduction is permitted which does not comply with these terms. 